\title{
The Estimation of the Socioeconomic and Environmental Impact of Rural Road Updating in Congo
}

\author{
Yuyan Liu ${ }^{1,2, a, *}$ Xinbo $\mathrm{Ma}^{2, b}$, Leijie $\mathrm{Xu}^{2, \mathrm{c}}$, Yang $\mathrm{He}^{3, \mathrm{~d}}$, and $\mathrm{Xin} \mathrm{Li}^{2, \mathrm{e}}$ \\ ${ }^{1}$ School of Traffic and Transportation, Beijing Jiaotong University, Beijing 100044, China. \\ ${ }^{2}$ School of Engineering, University of Birmingham, Birmingham B15 2TT, United Kingdom. \\ ${ }^{3}$ Beijing E-Hualu Information Technology Co., Ltd, Beijing 100043, China \\ ${ }^{a}$ *Corresponding author: 16120851@bjtu.edu.cn

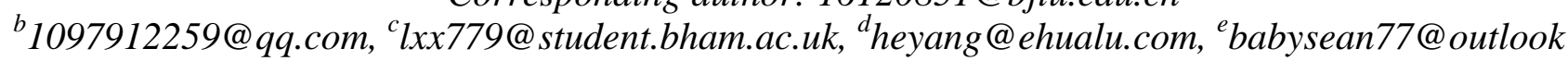 \\ .com
}

Keywords: Rural Road, Socioeconomic and Environmental Impact

Abstract: Rural road updating is one of the most effective approaches for local economy improvement, and the updated road may also influence the social and environmental development of the surrounding areas. This paper selects a section of rural road in Congo for upgrading research. The road is firstly divided into 15 sections and then the AHP method is used to address the issue of section ranking. Based on the assumptions and calculation results, it also discusses the social, economic and environmental impact of updating this road. As an example of the impact research of upgrading rural roads, this paper may provide basis for future studies.

\section{Introduction}

Democratic Republic of Congo, as a developing country in Africa, has vast territory and a $17^{\text {th }}$ most population in the world. It is extremely rich in natural resources but has little holistic development in economy because of some issues such as political instability, a lack of infrastructure and so on. Hence, it is essential to improve fundamental infrastructure to promote the development of the whole country. Rural road updating is one of approaches, which could boost national social and economic development.

The paper selects a section of rural road from the city of Nguba to Lubudi $(144 \mathrm{~km})$ for upgrading research. Through analyze existing socio-economic and environmental status, different degrees of development in these aspects are forecasted under conditions where some road sections are upgraded. It is not qualitative analysis because Analytic Hierarchy Process (AHP) is utilized to express the extent of impacts in value. The priority results represent clearly which road section is more urgent to be upgraded and the corresponding impact of upgrade work.

\section{Literature review}

There have been various studies attempted to search what would affect road reconstruction or verse visa. Majority of them concentrated on socio-economic and environmental aspects. For 
instance, to test whether transportation infrastructure is an enabler of social development, Haskins [1] collected empirical evidence in North Carolina and indicated that improving rural road can make demographic increase to some extent. Moreover, through several cases studied in Africa, Lombard and Coetzer [2] estimated the economic impact of rural road investment. It stated that the impacts could be measured in terms of direct benefits (reduce travel time and traffic operation costs), indirect benefits (increase employment opportunities) as well as induced benefits (improve accessibility to markets and promote economic activities). The socio-economic impact has also been pursued by other scientists, such as searching relationship between the rural road extension and poverty reduction [3].

At the meantime, some literature demonstrated the significance of road improvement for local environment. Hua [4] indicated that the environmental impact of rural road construction has two forms. Firstly, it will slip the flora and fauna in geographical structure; secondly, it will change the forest ecosystem. Hence, the environmental condition and the existing road condition should be considered.

\section{Methodology}

For the issue how to upgrade the road section from Nguba to Lubudi, the article firstly divides this section into 15 road sections with each section have a length of $10 \mathrm{~km}$ (except section15 with a length of $4 \mathrm{~km}$ ). With all the literature reviewed above, it is unreasonable, however, to claim which section should be updated first depending qualitatively on the socio-economic and environmental impacts. An approach that can convert the qualitative measurement into quantitative measurement is essential. The essay adopts AHP for making the upgrading process as a multi-objective, multicriteria and multi-level decision problem.

AHP, based on mathematics and psychology, is a structured technique for making complex decisions [5]. Larson and Ernest [6] said it has been applied by highway engineers for first time to do the preliminary condition evaluation of the Virginia highway program, and determining the best range of road project, which is similar to the issue.

\section{AHP for Ranking Priorities results}

\subsection{Building Analytic Hierarchy structure}

Based on the basic procedures of AHP and influential factors of the road improvement plan, a three-level analytic hierarchy structure is built up, as shown in Figure 1.

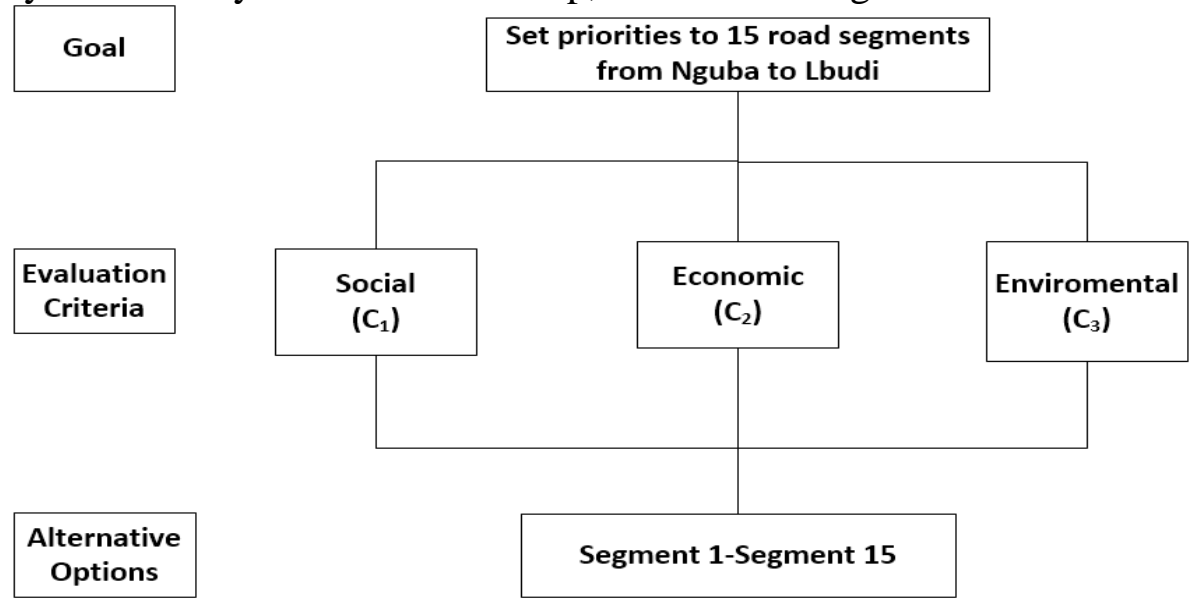

Figure 1. Analytic Hierarchy Structure for Sections Ranking. 
As can be seen in figure 1, the top level is the objective, setting priorities to 15 sections. There evaluation factors, Social (C1), economic (C2), environmental (C3), composes the second level. That is the evaluation criteria. Finally, the alternative options level is 15 road sections.

\subsection{Selecting Criteria}

The second step of AHP process is the selection of the key criteria that will be used. Road infrastructure expansion can cause social and economic impact from six aspects, population distribution, traffic condition, production structure, health, marketing as well as education [3], which in turn, are considered as the impact indicators in the following step of establishing the hierarchy model. Similarly, climate, landform as well as animals and plants around the area are considered as environmental indicators. And the following set of six criteria has been accepted and grouped into three categories, as shown in Figure 2.

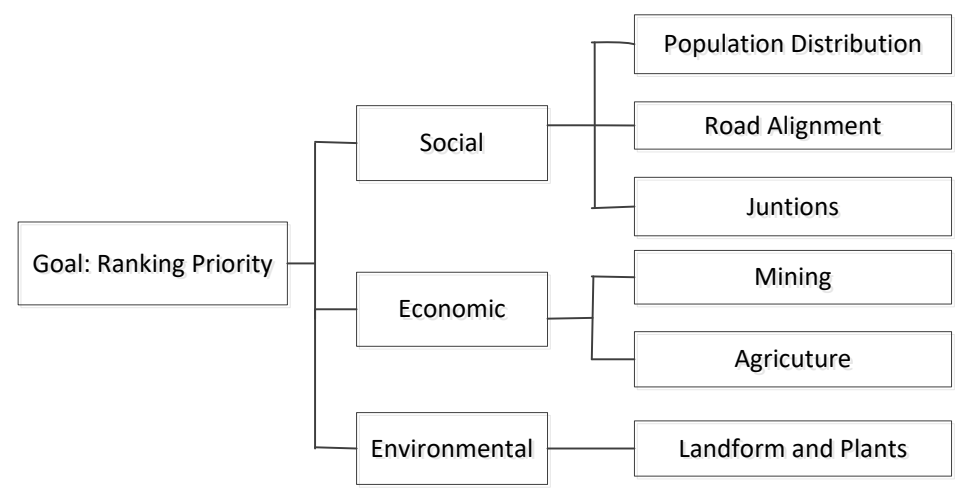

Figure 2. Hierarchy of Criteria for the ranking priority.

\subsection{Establishing the Hierarchical Model}

A three-level hierarchy model was then built up for this case study, as shown in Figure 3.

Goal:

Ranking priority to 15 road sections

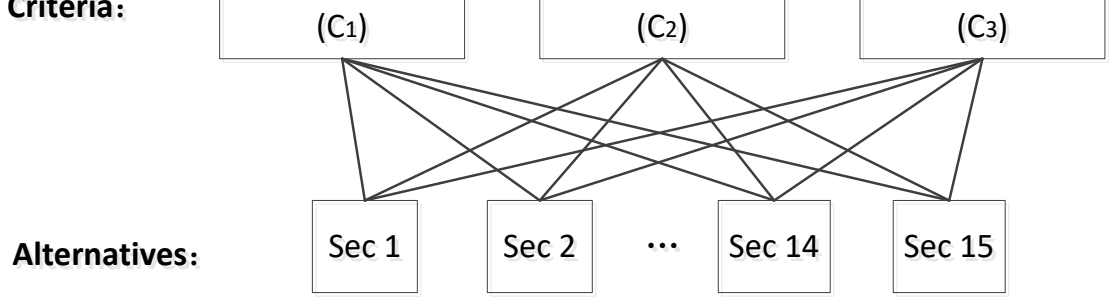

Figure 3. Analytic Hierarchy Structure for priority Rankings.

\subsection{Determine the comparison matrix, compute the eigenvectors and check the consistency}

To convert the qualitative evaluation into quantitative measurement, the article used the AHP pairwise comparison scale [5]. The scale gives a relative importance to one alternative when 
compared with another to define the significance of each alternative in numerical form. The comparison matrix will be an $\mathrm{m} \times \mathrm{m}$ matrix, where $\mathrm{m}$ is the number of criteria considered.

The evaluation process started at determining the weight of each criteria (C1, C2 and C3). The article established a matrix A according to decision makers, as shown in Formula 1.

$$
A=\left[\begin{array}{ccc}
1 & 2 & 4 \\
0.5 & 1 & 3 \\
0.25 & 0.333 & 1
\end{array}\right]
$$

In order to give weights to each road section, it is necessary to normalize the comparison matrix A. The process of normalization is to make the sum of the elements on each column equal to 1, i.e. each element $\bar{a}_{\mathrm{kj}}$ of the $A_{\text {norm }}$ is computed as Formula 2. And the result is shown in Formula 3.

$$
\begin{gathered}
\overline{\mathrm{a}}_{\mathrm{kj}}=\frac{\mathrm{a}_{\mathrm{kj}}}{\sum_{\mathrm{i}=1}^{\mathrm{m}} \mathrm{a}_{\mathrm{ij}}} \\
\mathrm{A}_{\text {norm }}=\left[\begin{array}{llc}
0.571 & 0.6 & 0.5 \\
0.286 & 0.3 & 0.375 \\
0.143 & 0.1 & 0.125
\end{array}\right]
\end{gathered}
$$

The article then calculated the principal eigenvalue $\lambda_{\max }$ using Formula 4, and the result is 4.112.

$$
\lambda_{\max }=\sum_{\mathrm{i}-1}^{\mathrm{m}} \frac{\mathrm{A} \cdot \mathrm{W}_{\mathrm{i}}}{\mathrm{nW}_{\mathrm{i}}}
$$

Where $W_{i}$ is the element of eigenvector $\omega^{(0)}$ and it was calculated by Formula 5.

$$
\mathrm{W}_{\mathrm{i}}=\frac{\overline{\mathrm{W}}_{\mathrm{i}}}{\sum_{\mathrm{j}=1}^{\mathrm{m}} \overline{\mathrm{W}}_{\mathrm{j}}}
$$

Where $\overline{\mathrm{W}}_{\mathrm{j}}=\sum_{\mathrm{j}=1}^{\mathrm{m}} \overline{\mathrm{a}}_{\mathrm{kj}}$. And the result of eigenvector $\omega^{(0)}$ is shown in Formula 6 .

$$
\omega^{(0)}=\left[\begin{array}{l}
0.557 \\
0.320 \\
0.123
\end{array}\right]
$$

The next step is checking the consistency of matrix A. To check whether the evaluations are consistent with each other, the article utilized the Consistency Index (CI), shown in Formula 7.

$$
\mathrm{CI}=\frac{\lambda_{\max }-m}{m-1}
$$

In order to verify whether the consistency index (CI) is adequate, Saaty [7] then suggests consistency rate (CR), shown in Formula 8, which is used to determine the consistency index and the random consistency index (RI).

$$
\mathrm{CR}=\frac{\mathrm{CI}}{R I}
$$

Since CR $<0.1 \sim 10 \%$, The comparison matrix can be considered to be consistent.

Just as what was done with the top level for the hierarchy model, it is necessary to calculate the contribution of each criteria for the second level of the hierarchy. The process is likely to the steps shown above, and three pairwise comparison matrices were created. After normalizing these matrices, the eigenvectors $s^{j}(j=1,2,3)$ were calculated and used to form the matrix of option scores S. Matrix S contains scores of every road section with each criterion is shown in table 1 below.

The eigenvalues $\lambda_{\max }^{j}(j=1,2,3)$ of these matrices were calculated afterward as 15.151, 15 and 15.237 respectively. Finally, the consistency indexes shown that all consistency rate is less than $10 \%$, which is expected to rank the final results. 
Table 1. The Matrix of Option Scores S.

\begin{tabular}{cccc}
\hline $\mathbf{S}$ & $\mathbf{S}^{\mathbf{1}}$ & $\mathbf{S}^{\mathbf{2}}$ & $\mathbf{S}^{\mathbf{3}}$ \\
\hline 1 & 0.042 & 0.088 & 0.133 \\
2 & 0.147 & 0.088 & 0.133 \\
3 & 0.076 & 0.088 & 0.013 \\
4 & 0.103 & 0.088 & 0.133 \\
5 & 0.117 & 0.088 & 0.013 \\
6 & 0.088 & 0.088 & 0.133 \\
7 & 0.019 & 0.088 & 0.013 \\
8 & 0.029 & 0.088 & 0.067 \\
9 & 0.087 & 0.088 & 0.067 \\
10 & 0.060 & 0.088 & 0.013 \\
11 & 0.073 & 0.088 & 0.067 \\
12 & 0.044 & 0.009 & 0.067 \\
13 & 0.014 & 0.009 & 0.017 \\
14 & 0.014 & 0.009 & 0.063 \\
15 & 0.088 & 0.009 & 0.067 \\
\hline
\end{tabular}

\subsection{Ranking Priority Results}

The global scores $\omega$ can be obtained by multiplying eigenvectors and option scores matrix S (shown in Formula 9). $\omega$ represent the final scores of all road sections considering all criteria in the model.

$$
\omega=S \cdot \omega^{(0)}
$$

The results are shown in Table 2 .

Table 2. Priorities Results.

\begin{tabular}{cccccccccccccccc}
\hline Sec. & $\mathbf{1}$ & $\mathbf{2}$ & $\mathbf{3}$ & $\mathbf{4}$ & $\mathbf{5}$ & $\mathbf{6}$ & $\mathbf{7}$ & $\mathbf{8}$ & $\mathbf{9}$ & $\mathbf{1 0}$ & $\mathbf{1 1}$ & $\mathbf{1 2}$ & $\mathbf{1 3}$ & $\mathbf{1 4}$ & $\mathbf{1 5}$ \\
\hline Rank & 8 & 1 & 7 & 2 & 3 & 4 & 12 & 11 & 5 & 9 & 6 & 13 & 15 & 14 & 10 \\
Score & 0.278 & 0.502 & 0.295 & 0.453 & 0.368 & 0.353 & 0.168 & 0.219 & 0.337 & 0.274 & 0.330 & 0.165 & 0.058 & 0.083 & 0.269 \\
\hline
\end{tabular}

According to the priority results, the first priority section is the section 2 which score is 0.50 and the following section is section 4 which score is 0.45. Apart from that, the scores of section5, section6, section9 and section 11 are similar, which are $0.36,0.35,0.33$ and 0.33 respectively. Besides, the scores of section3, section1, section10, section 15 and section 8 are in the range of 0.20 to 0.30 . Finally, the scores of section13 and section14 are less than 0.10 .

\section{Impact Discussion}

The section 2 is ranked at the first priority, which is because there are two cities in this section. That is to say, it has the highest density of population in the whole sections and the impact on socioeconomic of this section is more significant compared with others. So, the section 2 should be improved firstly. The second priority section is the section 4 . There are one big town and 3 villages in this section, which means that the density of population here is relatively high. Apart from that, there are $8 \mathrm{~T}$-junctions and 3 crossroads in this section, which means that there is a frequent use of the road and the traffic flow in this section will higher than other areas. Therefore, it is reasonable to believe that upgrading this section will further promote economic interaction since the newlyupgraded road will attract more customers from minor road.

For the sections (section7, section12, section13 and section14) whose scores are less than 0.20 , are the areas surrounded by grasslands and natural forest with fewer human activities. Once the unsealed road being upgraded to sealed or being widened, animals and plants living on both sides of 
the road will be isolated more seriously. If the number of these species is not huge enough, they will disappear gradually from this region, and bringing significant loss to the forest value. Therefore, these sections are unnecessary to be improved.

For the rest sections, it is not urgent for them to be upgraded. However, there will be plenty of benefits in boosting local economy if these sections are upgraded.

\section{Conclusion}

The article successfully applied AHP into setting road updating priorities from Nguba to Lubudi in Congo. These sections are all 10-kilometer-long road sections from Nuguba, except sec15 (sec15 is $4 \mathrm{~km}$ ). The results are clearly shown in numbers, which represent how urgent these sections are to be updated.

Socio-economic and environment impact are considered afterwards. For the socio-economic aspects, upgrading rural roads can increase road capacity and decrease journey time on the one hand. On the other, it can stimulate economic growth and then increase the income of residents. Besides, there is a positive impact on health system and education system, since upgraded rural road will improve hospital attendance and vaccination rates and the school-aged children will have more rights to choose a better school. For the environmental aspects, Newly-upgraded rural road will pass through natural forest and then intensify the slip of fauna and flora because of the widen road surface.

\section{References}

[1] C.B. Haskins. The Influence of Highways on Rural Economic Development: Evidence from North Carolina. University of North Carolina. (2002).

[2] P. Lombard and L. Coetzer. The Estimation of the Impact of Rural Road Investments on Socio-economic Development. International seminar on sustainable road financing \& investment. pp. 8-9. (2007).

[3] J. Hine, M. Abedin, R.J. Stevens, T. Airey and T. Anderson. Does the extension of the rural road network have a positive impact on poverty reduction and resilience for the rural areas served? A systematic review. London: EPPICentre, Social Science Research Unit, UCL Institute of Education (2015).

[4] D. Hua. The impact of Highway engineering on the flora and fauna and its mitigation measures. Traffic Environmental Protection. Volume 20: pp 40-45. (1998).

[5] T.L. Saaty. The Analytic Hierarchy Process. McGraw-Hill, New York. (1980).

[6] Larson C.D. Larson and Ernest H.F. Application of the Analytic Hierarchy Process to Select Project Scope for Videologging and Pavement Condition Data Collection. Transportation Research Board. (2007)

[7] T. L. Saaty Theory and applications of the analytic network process: Decision making with benefits, opportunities, costs, and risks. Pittsburgh: RWS. (2005). 